\title{
GAMBARAN KECEMASAN PADA WANITA PEKERJA TEMPAT HIBURAN MALAM (WANITA PENGHIBUR)
}

\author{
PICTURE OF ANXIETY ON WOMEN ENTERTAINMENT (WOMEN'S ENTERPRISE)
}

\author{
Hairul \\ Fakultas Psikologi, Universitas 17 Agustus 1945 Samarinda \\ Email: irul.psikologi2011@gmail.com
}

\begin{abstract}
Abstrak: Kecemasan adalah perasaan sangat tidak nyaman, berupa ketidakpastian tentang sesuatu yang belum terjadi, diikuti oleh adanya sensasi tubuh. Wanita pekerja tempat hiburan malam yang biasa disebut dengan wanita penghibur merupakan pekerjaan yang banyak memiliki risiko untuk timbulnya kecemasan.Tujuan dari penelitian ini adalah untuk mendapatkan gambaran kecemasan yang dirasakan oleh wanita pekerja tempat hiburan malam (wanita penghibur).Penelitian ini termasuk penelitian deskriptifkualitatifdenganteknik pengambilan data melalui observasi, wawancara, dan dokumentasi. Dari hasil penelitian ini didapatkan bahwa penyebab Subjek bekerja sebagai wanita penghibur adalah sebagai bentuk pelarian, kemudian faktor ekonomi dan mudahnya mendapatkan uang menjadi pendorong untuk tetap bertahan pada pekerjaan itu. Didapatkan 4 faktor timbulnya kecemasan pada wanita pekerja tempat hiburan malam yaitu sebagai berikut: kecemasan terhadap menurunnya kesehatan dengan tingkat kecemasan ringan, kecemasan moral dengan tingkat kecemasan ringan, kecemasan terhadap razia dengan tingkat kecemasan berat, dan kecemasan terhadap kekerasan dan pelecehan seksual dengan tingkat kecemasan sedang hingga panik.
\end{abstract}

Kata Kunci: Kecemasan, Wanita Penghibur

Abstract: Anxiety is an uncomfortable feeling, in the form of uncertainty about something that has not happened, followed by the presense of body sensations. Working as women workers at the night clubs whom often called as the woman entertainers is a work that has a lot of risks for the onset of anxiety. The purpose of this research is to get a sense of anxiety felt by women entertainers. This research is a qualitative descriptive study which using techniques of data collection through observation, interview, and documentation. As a result of this research found that the main factor of the Subject who work as an entertainer is as a form of escape, then the factor of economy and the convenience to get money is the motivation factors to stay afloat at their work. There are four factors discovered in the emergence of anxiety on women workers at the night clubs just as follows: anxiety of health declining with low level of anxiety, moral anxiety with low level of anxiety, the anxiety about the raid with high level of anxiety, and anxiety of violence and sexual abuse with medium level of anxiety going to panic.

Keywords: Anxiety, The Women Entertainers

Jurnal Motiva

Hairul 


\section{PENDAHULUAN}

Wanita adalah manusia yang diciptakan Tuhan untuk mendampingi laki-laki, yang diberikan karunia organ reproduksi sehingga dapat mengandung, melahirkan, dan menyusui. Pada budaya khususnya di Indonesia pada zaman dulu mengharuskan wanita untuk tinggal di rumah dan prialah yang bekerja untuk mencari nafkah, namun dengan seiring berjalannya waktu, wanita juga mulai banyak yang bekerja untuk memenuhi kebutuhan ekonomi. Fenomena wanita bekerja sebenarnya bukanlah fenomena baru yang muncul kemarin sore, melainkan sejak zaman awal diciptakannya manusia. Hanya cara dan istilahnya yang berbeda pada masing-masing zaman. Menjadi wanita tidaklah semudah yang dibayangkan oleh seorang pria tentang wanita. Apalagi wanita Indonesia, yang masih sangat kental dengan budaya ketimuran, yang selalu memandang wanita adalah sebagai seorang ibu yang anggun, halus, lemah lembut, selalu dekat dengan keluarga, dengan kasih sayangnya membesarkan buah hatinya, dan sebagainya. Perumpamaan dan istilah itu sepertinya hanya layak diberikan kepada kaum wanita saja. Keterlibatan wanita yang sudah kentara membawa dampak terhadap peran wanita dalam kehidupan keluarga. Selain karena didorong oleh kebutuhan ekonomi keluarga, juga wanita semakin dapat mengekspresikan dirinya di tengah-tengah keluarga dan masyarakat. Keadaan ekonomi keluarga mempengaruhi kecenderungan wanita untuk berpartisipasi di luar rumah, agar dapat membantu meningkatkan perekonomian keluarga.

Motivasi untuk bekerja dengan mendapat penghasilan khususnya untuk wanita golongan menengah tidak lagi hanya untuk ikut memenuhi kebutuhan ekonomi keluarga, melainkan juga untuk menggunakan keterampilan dan pengetahuan yang telah mereka peroleh serta untuk mengembangkan dan mengaktualisasikan diri.

Wanita penghibur yang bekerja di tempat hiburan malam juga termasuk dalam kelompok masyarakat. Tapi berbeda dengan PSK (Pekerja Seks Komersial) yang bekerja dengan cara menawarkan "jasa" seks kepada konsumen dan mendapatkan uang sebagai imbalan, wanita penghibur bekerja dengan menawarkan "jasa", biasanya hanya menemani duduk, memandu karaoke, tapi juga biasanya mereka meminum minuman keras.Menjadi wanita penghibur sangat rentan dengan menurunnya kesehatan, hal ini dikarenakan menjadi wanita penghibur di tempat hiburan malam diharuskan untuk dapat mengkonsumsi minuman beralkohol, karena itu adalah salah satu dari job descmereka. Dengan mengkonsumsi alkohol yang terus menerus akan berdampak buruk pada kesehatan terutama pada organ hati.

Memikirkan dampak negatif yang ditimbulkan oleh pekerjaan tersebut maka kemungkinan akan menimbulkan berbagai kecemasan. Menurut Muchlas (dalam Ghufron \& Risnawita, 2010) mendefinisikan istilah kecemasan sebagai suatu pengalaman subjektif mengenai ketegangan mental kesukaran dan tekanan yang menyertai konflik atau ancaman.

Kecemasan cenderung menghasilkan kebingungan dan distorsi persepsi, tidak hanya pada ruang dan waktu tetapi pada orang dan arti peristiwa. Distorsi tersebut dapat mengganggu dan menurunkan kemampuan memusatkan perhatian, menurunkan daya ingat, dan mengganggu kemampuan untuk menghubungkan satu hal dengan hal lain (Kaplan dan Dadock dalam Febrianti, 2009).

Tempat karaoke yang menyediakan wanita penghibur juga menjadi salah satu ladang uang bagi para wanita penghibur, seperti yang terjadi di TanjungPinang. Sebuah tempat karaoke diduga menjadi tempatnya para pria hidung belang menikmati hiburan malam dengan wanita panggilan yang menjual jasanya dengan menerima uang tip dari para pria hidung belang yang memanggil untuk berkaraoke. Kebanyakan yang menjajal diri seperti itu dilakukan para gadis yang berumuran 18 tahun hingga 25 tahun, karena sangat mudah untuk mencari uang jajan atau biasa disebut dengan uang tip. Para wanita itu hanya bermodalkan kecantikan dan berpakaian menarik agar bisa membuat para tamu tertarik dengan jasanya untuk menemani karaoke.

Bekerja sebagai wanita penghibur di tempat karaoke memang membuat pandangan 
masyarakat menjadi buruk. Bahkan jika wanita tersebut sudah berhenti bekerja di tempat itu tetap mendapat pandangan buruk dari orang sekitar. Seperti yang dirasakan oleh penyanyi dangdut pendatang baru, Cita Citata. Dilansir di sebuah halaman web (detik.com) pada Jumat, 26 desember 2014, Cita Citata dicela karena merupakan mantan gadis karaoke. Cita Citata mengakui dirinya pernah menjadi wanita karaoke selama beberapa bulan di kawasan Tangerang. Pernyataan Cita Citata tersebut pun akhirnya berbuah celaan untuk dirinya sendiri.

\section{METODE PENELITIAN}

Penelitian ini merupakan penelitian kualitatif deskriptif dengan mengambil dua orang subjek dan satu orang sighnificant other. Penelitian dilakukan dengan wawancara kemudian hasil wawancara di beri koding untuk mendapatkan hasil interprestasi.

Penelitian dilaksanakan pada waktu dan tempat yang berbeda bagi setiap subjek yang diwawancara, beberapa tempat penelitian tersebut diantaranya mitra pub and café, muse resto lantai 8 samarinda, mess mitra pub and café dan satu tempat yang tidak bisa dipublikasikan(dirahasiakan).Jenispenelitiandes kriptifkualitatifyangdigunakanpadapenelitianini dimaksudkanuntukmemperolehinformasimenge naikecemasan terhadap penurunan harga diri pada wanita yang bekerja sebagai penghibur di Tempat Hiburan Malam secara mendalamdankomprehensif.Selainitu,denganpen dekatankualitatifdiharapkan

dapatdiungkapkansituasidanpermasalahanyangd ihadapidalamkegiatan partisipasi.

Objek dari penelitian ini adalah kecemasan pada wanita yang bekerja di Tempat Hiburan Malam. Yang dimaksud dengan kecemasan pada wanita yang bekerja di Tempat Hiburan Malam adalah rasa kekhawatiran, tidak aman, gelisah, dan ketakutan yang dirasakan oleh wanita yang bekerja di Tempat Hiburan Malam akan berbagai hal yang terjadi di suatu waktu karena dampak buruk yang berasal dari pekerjaannya seperti turunnya kesehatan, telah menyalahi norma-norma moral dan agama, turunnya harga diri dan adanya razia di Tempat Hiburan Malam tersebut.
Subjek dari penelitian ini adalah wanita yang bekerja di Tempat Hiburan Malam khususnya di Mitra Pub dan Cafe Samarinda. Terdapat 2 orang Subjek dalam penelitian ini dan satu orang Significant Other.

Yang menjadi Significant Other dalam penelitian ini adalah Captain Ladies atau Kapten dari kedua Subjek. Peneliti menentukan kapten wanita penghibur ini sebagai significant other karena peneliti yakin ia sangat mengenal kedua subjek dan kapten wanita penghiburlah yang biasanya menjadi tempat aduan bagi para wanita penghibur ketika memiliki masalah dalam pekerjaan mereka.

\section{HASIL DAN PEMBAHASAN}

Data dari hasil penelitian ini didapatkan melalui wawancara mendalam yang dilakukan pada bulan Agustus 2015. Dalam penelitian ini ada 2 orang yang menjadi Subjek penelitian dan 1 orang yang menjadi Significant Other yaitu Kapten dari kedua Subjek.

Diperoleh beberapa tema yang mengarah pada jawaban dari pertanyaan penelitian berupa penyebab bekerja, kecemasan terhadap menurunnya kesehatan, kecemasan moral, kecemasan saat terjadi razia, dan kecemasan terhadap kekerasan dan pelecehan seksual.

Berikut adalah hasil analisis berdasarkan sudut pandang Subjek sebagai wanita penghibur:

\section{Dinamika Pengalaman}

a) Penyebab Bekerja

1. Pelarian dari Masalah

Kedua Subjek mengatakan penyebab utama mereka memilih pekerjaan sebagai wanita penghibur adalah sebagai pelarian dari masalah. Masalah yang dimaksud lebih kepada masalah di dalam keluarga dan kehidupan pribadi.

Seperti yang dikatakan Ny. Dn,"Yang pertama karena sebagai pelarian, karena gue dulu pernah juga ngelamar kerja di konter hp buat jualan pulsa sama aksesorisnya, tapi 
gajinya gak seberapa sedangkan kebutuhan gue juga banyak, gak sebanding gitu." (S1W1.3-8).

\section{Kebutuhan Ekonomi}

Minimnya upah yang diperoleh di tempat kedua Subjek bekerja sebelumnya, jika diperuntukan untuk memenuhi kebutuhan sehari-hari akan masih sangat kurang bagi kedua Subjek. Kebutuhan ekonomi menjadi alasan selanjutnya yang mendorong mereka untuk bekerja sebagai wanita penghibur, seperti yang diungkapkan oleh Ny. Dn: "Sedangkan kebutuhan gue kan banyak, jadi gak sebanding gitu, emang mau minta sama siapa lagi? Uang kan gak datang sendirinya dari langit." (S1.W1.5-7).

3. Penghasilan yang Banyak

Penghasilan yang di atas ratarata jika bekerja di tempat lain membuat daya tarik selanjutnya bagi para wanita penghibur untuk pengambilan keputusan. Ketika peneliti bertanya kepada Ny. Dn apakah teman yang mengajaknya untuk bekerja sebagai wanita penghibur itu menjanjikan penghasilan yang banyak? Dan ia menjawab,"Gak, dia gak janjiin penghasilan gede, tapi kan secara kita ya walaupun orang awam sekalipun juga pasti bakal taulah kalau pekerjaan yang seperti itu pasti uangnya banyak, lagian juga kan teman gue tuh gue lihat kehidupannya serba cukup sekarang sampai adiknya bisa sekolah gitu." (S1.W1.12-15).

b) Kecemasan

1. Kecemasan Terhadap Turunnya Kesehatan

2. Kedua Subjek memiliki pandangan yang sama terhadap dampak yang ditimbulkan dari pekerjaan mereka.
Kecemasan Moral. Hampir setiap orang menilai pekerjaan sebagai wanita penghibur adalah salah satu dari penyakit masyarakat, dimana pekerjaan tersebut adalah pekerjaan yang menyalahi banyak norma-norma dan memiliki nilai moral yang buruk. Kedua Subjek menyadari akan pandangan buruk orang sekitar terhadapnya, seperti yang dikatakan Ny. Anggita, "Pasti kamu kira kami nih kafir banget kan, tau aja aku apa di pikiran orang tentang kami." (S2.W1.73-74).

\section{Kecemasan Saat Terjadi Razia}

Ada berbagai bentuk razia yang sering beroperasi di sebuah Tempat Hiburan Malam. Salah satunya adalah razia yang dilakukan oleh pihak BNN yang mencari pengguna narkotika untuk direhabilitasi dengan cara tes urin. Sehubungan dengan kedua Subjek yang juga adalah pengguna narkotika, maka razia dari $\mathrm{BNN}$ adalah pencetus berbagai jenis kecemasan bagi mereka. Dari kecemasan ringan, sedang, berat, hingga panik.

4. Kecemasan Terhadap Kekerasan dan Pelecehan Seksual

Kedua Subjek mengatakan hal yang sama mengenai pandangan mereka terhadap sebagian besar pelanggannya, yaitu setiap pelanggannya memiliki pikiran yang tidak baik terhadap mereka. Bahkan jika sudah dalam pengaruh alkohol, emosi para pelanggan menjadi tidak stabil, hal itu yang menimbulkan ketakutan bagi para wanita penghibur akan terjadinya kekerasan hingga pelecehan seksual.

c) Dampak Kecemasan

1. Kecemasan Terhadap Menurunnya Kesehatan

Kedua Subjek sering menyalah artikan gejala penyakit ringan seperti 
influenza sebagai gejala penyakit berat seperti TBC.

2. Kecemasan Moral

Baik Ny. Anggita maupun Ny. Dn, keduanya memiliki kecemasan yang sama terhadap penyalahan nilai-nilai moral yang mereka lakukan.

3. Kecemasan Saat Terjadi Razia

Dampak kecemasan yang ditimbulkan saat terjadi razia terutama razia dari pihak $\mathrm{BNN}$ bermacam-macam pada setiap wanita penghibur yang merasa menggunakan narkotika, ada yang bersembunyi di tempat manapun.

4. Kecemasan Terhadap Kekerasan dan Pelecehan Seksual

Dampak yang ditimbulkan dari kecemasan terhadap kekerasan dan pelecehan seksual sangat beragam. Kedua Subjek memiliki pengalaman yang buruk terhadap kekerasan dan pelecehan seksual (pencobaan pemerkosaan) yang pernah mereka alami di masa lalu saat bekerja.

2. Makna

a) Makna Penyebab Bekerja

1. Pelarian dari Masalah

Pelarian dari masalah adalah faktor utama bagi kedua Subjek memilih untuk menjadi wanita penghibur.

2. Kebutuhan Ekonomi

Kedua Subjek terlahir dari keluarga yang kurang mampu dalam segi ekonomi.

3. Penghasilan Yang Banyak

Dengan penghasilan yang banyak, maka hal itu yang menambah keinginan kedua responden untuk tetap menggeluti pekerjaan tersebut.

b) Makna Kecemasan

1. Kecemasan Terhadap Menurunnya Kesehatan
Kecemasan yang dirasakan kedua Subjek untuk menurunnya kesehatan adalah jenis kecemasan neoritis dengan tingkat kecemasan ringan. Kecemasan neoritis yang dimaksud adalah adanya rasa takut terhadap dampak negatif dari pemenuhan kebutuhan yang dilakukan oleh kedua Subjek.

2. Kecemasan Moral

Makna kecemasan yang dirasakan kedua Subjek akan pandangan mereka terhadap pekerjaan yang salah, lingkungan yang memusuhi, dan penyalahan norma-norma adalah kecemasan moral dengan tingkat kecemasan ringan.

3. Kecemasan Saat Terjadi Razia

Pada kecemasan yang dirasakan kedua Subjek saat terjadi razia, ditemukan jenis kecemasan neoritis dengan tingkat kecemasan berat. Kecemasan neoritis yang muncul adalah ketakutan akan terkena hukuman karena pemenuhan kebutuhan Id yang tidak sejalan dengan Superego.

4. Kecemasan Terhadap Kekerasan dan Pelecehan Seksual

Pada kecemasan ini memiliki makna kecemasan dengan jenis kecemasan objektif dan tingkat kecemasan sedang hingga panik. Kecemasan realitas adalah kecemasan yang memiliki objek atau bentuk nyata seperti kecemasan pada tindak kekerasan dan pelecehan seksual.

\section{PEMBAHASAN}

Dari hasil penelitian ditemukan kedua Subjek bekerja sebagai wanita penghibur karena adanya dorongan dari dalam diri mereka. Dorongan tersebut berupa keinginan untuk melepaskan masalah yang mereka alami ketika itu ditambah dengan kebutuhan ekonomi 
yang sangat mendesak, juga mudahnya mendapatkan uang pada pekerjaan tersebut.

Dalam penelitian ini ditemukan berbagai gambaran kecemasan yang dirasakan oleh wanita pekerja Tempat Hiburan Malam, seperti:

1. Kecemasan Terhadap Menurunnya Kesehatan

Pada kecemasan terhadap menurunnya kesehatan, didapatkan aspek kecemasan neoritis dengan tingkat kecemasan ringan.

2. Kecemasan Moral

Pada kecemasan moral, didapatkan aspek kecemasan moral dengan tingkat kecemasan ringan.

3. Kecemasaan Saat Terjadi Razia

Dalam hal kecemasan ini, didapatkan jenis kecemasan neoritis dengan tingkat kecemasan berat.

4. Kecemasan Terhadap Kekerasan dan Pelecehan Seksual

Pada kecemasan ini didapatkan jenis kecemasan objektif dengan tingkat kecemasan sedang hingga panik.

\section{KESIMPULAN}

Secara keseluruhan terungkap bahwa para Subjek yang bekerja sebagai wanita penghibur awalnya sebagai bentuk pelarian. Pelarian yang dimaksudkan adalah pelarian dari masalah. Kedua Subjek memiliki masalah yang menjadi beban dalam kehidupan sehari-harinya. Kemudian faktor ekonomi menjadi pendorong mereka dalam memantapkan pilihan untuk menjadi wanita penghibur tersebut. Mudahnya mendapatkan uang pada pekerjaan tersebutlah yang akhirnya mendorong kedua Subjek untuk tetap bertahan menggeluti pekerjaan sebagai wanita penghibur. Di dalam penelitian ini ditemukan 4 faktor yang menjadi kecemasan kedua Subjek yaitu sebagai berikut: Kecemasan Terhadap Menurunnya Kesehatan, Kecemasan moral, kecemasan saat terjadi razia dan kecemasan terhadap kekerasan dan pelecehan seksual.

\section{DAFTAR PUSTAKA}

Andri dan Yeni, D. 2007. Teori Kecemasan Berdasarkan Psikoanalisis Klasik dan Berbagai Mekanisme Pertahanan Terhadap Kecemasan, 57, 233-239.

Anonimus. http://artikata.com/arti-333668kelab.html, diakses pada tanggal 9 Mei 2015, pukul 14:00 WITA.

Anonimus. http://hot.detik.com/read/citacitata-dicela-karena-mantan-gadiskaraoke-ivan-gunawan-berikansemangat, diakses pada tanggal 23 $\underline{\text { Mei 2015, pukul 13:14 WITA. }}$

Anonimus.

http://www.isukepri.com/2013/11/kara oke-jadi-ladang-cari-uang-wanitapenghibur/\#, diakses pada tanggal 23 Mei 2015, pukul 13:28 WITA.

Febrianti, K. 2009. Gambaran Gejala Kecemasan Tenaga Kerja Wanita Indonesia Menjelang Keberangkatan Pertama Kali ke Luar Negeri

Ghufron, M. N. dan Risnawita, R. 2010. Teori-Teori Psikologi. Jakarta: ArRuzz Media.

Hergenhahn, B. R. dan Matthew, H. 2013. Pengantar Teori Kepribadian edisi kedelapan. Jakarta: Pustaka belajar.

Kusuma, W. 2010. Pengantar Psikologi edisi ke-sebelas Jilid 1. Batam: Interaksara.

Musfir \& Zahroni, S. 2005. Konseling Terapi. Jakarta: Gema Insani, 512. 
Peter, J. dan Cathrine. 2011. Gambaran Kecemasan Terhadap Pekerja Seks Komersial (PSK) di Bandung.

Ratih, N. K. 2012. Hubungan Tingkat Kecemasan Terhadap Koping Siswa SMUN 16 dalam Menghadapi Ujian Nasional.17-38.

Sihombing, J. dan Hutagalung, K. 2011. Gambaran Kecemasan Pada Pekerja Seks Komersial (PSK) di Bandung. Jurnal Universitas Kristen Maranatha, Vol 11 No.1.
Sugiono. 2011. Metode Penelitian Kuantitatif, Kualitatif, dan R\&D. Bandung: Alfabeta.

Semiun, S. 2013. Teori-Teori Kepribadian jilid 2. Yogyakarta: KANSIUS.

Tim MGBK. 2010. Bahan Dasar Untuk Pelayanan Konseling Pada Satuan Pendidikan Menengah Jilid 1. Jakarta: PT.Grasindo. 